\section{Outcomes of Patients with Takayasu Arteritis Treated with Infliximab}

To the Editor:

Takayasu arteritis (TA) is a chronic vasculitis of unknown etiology involving the aorta and its main branches. Progression may lead to stenosis or formation of aneurysms ${ }^{1}$. Current therapy is based on corticosteroids and immunosuppressive agents. Treatment with anti-tumor necrosis factor- $\alpha$ (anti-TNF- $\alpha$ ) has shown efficacy, as well as unfavorable outcomes $2,3,4,5,6,7$. From a cohort of 14 patients with TA refractory to conventional treatments, we treated 3 with infliximab (IFX), and describe the outcome.

Case 1. A 21-year-old woman was admitted because of 6 months of progressive chest pain, palpitations, and claudication in the left upper limb. Examination showed differential blood pressure between arms, decreased pulses in the left arm, bilateral carotid, and mitral murmur; erythrocyte sedimentation (ESR) rate was $54 \mathrm{~mm} / \mathrm{h}$ and C-reactive protein (CRP) was $3 \mathrm{mg} / \mathrm{dl}$. Angiography study showed stenosis in the thoracic aorta and supraaortic and renal vessels compatible with a diagnosis of TA. Initially she was treated with prednisone $1 \mathrm{mg} / \mathrm{kg} /$ day and azathioprine $2 \mathrm{mg} / \mathrm{kg} / \mathrm{day}$ for 2 months, without a favorable response. Azathioprine was changed to methotrexate (MTX) $10 \mathrm{mg}$ weekly. One month later, her clinical condition was unchanged, and we started treatment with IFX $3 \mathrm{mg} / \mathrm{kg}$ on days 0,14 , and 45; and then every 2 months for 6 months. Because of an unfavorable response, we increased the dose to $5 \mathrm{mg} / \mathrm{kg}$ every 2 months. She was asymptomatic with normal ESR and CRP for 2 years. Then she developed chest pain, and angiography revealed obstruction of the left main coronary artery (Figure 1) and an aneurysm of the descending aorta. A coronary stent was installed, which resulted in symptomatic control. Tocilizumab $8 \mathrm{mg} / \mathrm{kg}$ monthly was useful for subsequent disease control.

Case 2. A 27-year-old woman was admitted with claudication in the lower limbs and abdominal pain. Examination revealed different blood pressures

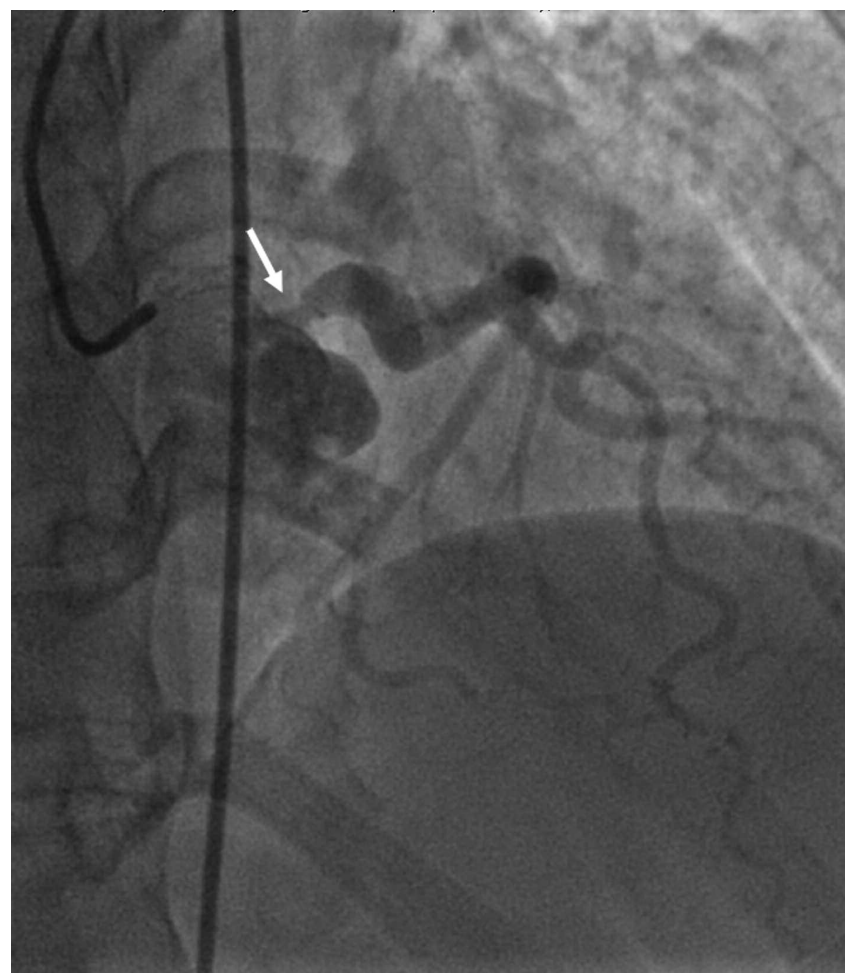

Figure 1. Outcome after infliximab therapy in Patient 1; there is $60 \%$ occlusion of the left coronary artery (arrow) between the upper limbs. Carotid and left subclavian vessel bruits were auscultated, and a murmur associated with a pulsatile mass on hypogastrium was found. ESR was $38 \mathrm{~mm} / \mathrm{h}$. A whole-body angio-computed tomography (CT) study showed aneurysms in the descending thoracic aorta and at the aorto-iliac bifurcation, and stenosis in supra-aortic vessels. She was diagnosed with TA. She received methylprednisolone pulses and was discharged with prednisone $25 \mathrm{mg}$ daily and MTX $10 \mathrm{mg}$ weekly. Two months later, cyclosporine $100 \mathrm{mg} /$ day was added because there had not been a favorable response. One month later, the symptoms persisted and ESR and CRP were high. IFX $3 \mathrm{mg} / \mathrm{kg}$ on days 0,14 , and 45 and then 5 $\mathrm{mg} / \mathrm{kg}$ every 2 months was indicated. Three years later, she developed severe cough and anterior thoracic pain. Angio-CT showed increased size of the aortic thoracic aneurysm with imminent rupture to the left bronchus (Figure 2). An endovascular stent graft was installed as described ${ }^{8}$. Subsequently she has been treated with prednisone $10 \mathrm{mg}$ and cyclosporine $100 \mathrm{mg}$ each day, with acceptable disease control.

Case 3. A 23-year-old woman was admitted because of oppressive chest pain, dyspnea, headache, blurred vision, hypertension, and chronic anemia. Examination demonstrated a murmur in the anterior chest and abdomen. ESR was $54 \mathrm{~mm} / \mathrm{h}$. Angiographic study showed occlusion of supra-aortic vessels and descending and superior abdominal aorta consistent with TA Control of symptoms was not achieved with conventional treatment (MTX $15 \mathrm{mg}$ weekly, prednisone $50 \mathrm{mg} /$ day, cyclosporine $200 \mathrm{mg} /$ day). Ten months later, IFX $3 \mathrm{mg} / \mathrm{kg}$ was started. She developed angina pectoris, with increased ESR and CRP. A left coronary revascularization procedure was necessary. Because of persistence of general symptoms and high ESR, monthly tocilizumab $8 \mathrm{mg} / \mathrm{kg}$ was initiated. Two years later there is acceptable disease control.

TA is characterized by the presence of granulomatous inflammation at the middle layer of affected vessels, generating stenosis or aneurysms ${ }^{9}$. In

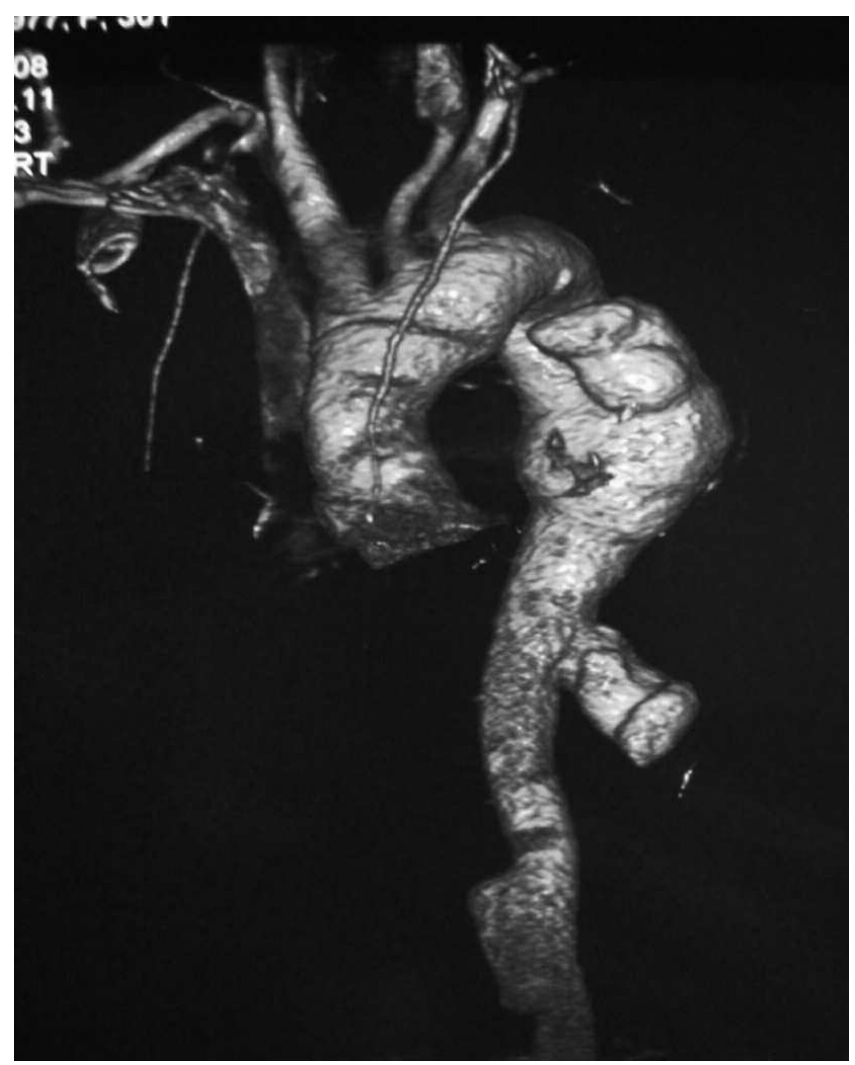

Figure 2. In Patient 2, thoracoabdominal angio-computed tomography revealed saccular aneurysms of descending thoracic aorta. 
active phases of this process various cytokines have been implicated in pathogenesis, including TNF- $\alpha$ and interleukin 6 (IL-6) ${ }^{1}$. Anti-TNF- $\alpha$ therapy has been considered after failure of conventional therapy. The outcomes have been described in case reports ${ }^{2,3,4,5,6}$. Schmidt, et al ${ }^{4}$ reported improvement in more than $80 \%$ of patients. Some authors have described lack of response and even worsening progression with anti-TNF- $\alpha$ therapy ${ }^{2,7}$. We describe 3 cases with apparent disease control for several months after IFX treatment; yet the disease progression continued, with worsening vascular stenosis or aneurysm that required invasive vascular procedures. Two patients were treated subsequently with tocilizumab, with a good outcome for at least 2 years.

Further studies are needed to establish the true role of these drugs in the treatment of TA.

FABIO BONILLA-ABADÍA, MD, Unit of Rheumatology; CARLOS ALBERTO CAÑAS, MD, Unit of Rheumatology; ANDRÉS FELIPE ECHEVERRI, MD, Unit of Internal Medicine, Fundación Valle del Lili, CES University, Cra. 98 18-49, Cali, Colombia. Address correspondence to Dr. Cañas; E-mail: cacd12@hotmail.com

\section{REFERENCES}

1. Arnaud L, Kahn JE, Girszyn N, Piette AM, Bletry O. Takayasu's arteritis: An update on physiopathology. Eur J Intern Med 2006;17:241-6.

2. Hoffman GS, Merkel PA, Brasington RD, Lenschow DJ, Liang P. Anti-tumor necrosis factor therapy in patients with difficult to treat Takayasu arteritis. Arthritis Rheum 2004;50:2296-304.
3. Tatò F, Rieger J, Hoffmann U. Refractory Takayasu's arteritis successfully treated with the human, monoclonal anti-tumor necrosis factor antibody adalimumab. Int Angiol 2005;24:304-7.

4. Schmidt J, Kermani TA, Bacani AK, Crowson CS, Matteson EL, Warrington KJ. Tumor necrosis factor inhibitors in patients with Takayasu arteritis: Experience from a referral center with long-term followup. Arthritis Care Res 2012;64:1079-83.

5. Molloy ES, Langford CA, Clark TM, Gota CE, Hoffman GS. Anti-tumour necrosis factor therapy in patients with refractory Takayasu arteritis: Long-term follow-up. Ann Rheum Dis 2008;67:1567-9.

6. Mekinian A, Néel A, Sibilia J, Cohen P, Connault J, Lambert M, et al. Efficacy and tolerance of infliximab in refractory Takayasu arteritis: French multicentre study. Rheumatology 2012;51:882-6.

7. Osman M, Aaron S, Noga M, Yacyshyn E. Takayasu's arteritis progression on anti-TNF biologics: a case series. Clin Rheumatol 2011;30:703-6.

8. Bonilla-Abadía F, Echeverri AF, Carbonell JP, Cañas CA. Multiple endovascular stent-graft implantations in a patient with aortic thoracic and abdominal aneurysms due to Takayasu arteritis. Rheumatol Int 2013 Jan 5. [E-pub ahead of print].

9. Cañas CA, Jimenez CA, Ramirez LA, Uribe O, Tobón I, Torrenegra A, et al. Takayasu arteritis in Colombia. Int J Cardiol 1998;66 Suppl 1:S73-9.

J Rheumatol 2013;40;11; doi:10.3899/jrheum.130154 